\title{
Magnetic resonance imaging findings of patients with suspected tuberculosis from a tertiary care centre in Sri Lanka
}

\author{
A S Pallewatte ${ }^{1}$, N A Wickramasinghe ${ }^{1}$
}

(Index words: spinal tuberculosis, MRI, imaging)

\begin{abstract}
Introduction Spinal tuberculosis (TB) is a relatively common cause for spinal pathology in Sri Lanka and a common indication for magnetic resonance imaging (MRI).

Objectives The objective of the study was to describe the MRI imaging pattern of spinal TB in a series of patients.

Methods One hundred and nine patients with clinically confirmed spinal tuberculosis who had undergone MRI scans at the National Hospital of Sri Lanka from 2012-2016 were included in the study.

Results The commonest vertebral level of spinal TB involvement was at L4/5 level, followed by L5/S1 level. L5 vertebral body involvement was the commonest and L4 was second commonest. Single level involvement $(68.8 \%)$ was commoner than multiple $(31.2 \%)$ involvement or contiguous involvement. Wedging $(24.8 \%)$, erosions (89\%), end plate changes (96.3\%), canal stenosis $(77.1 \%)$, paravertebral collection $(65.1 \%)$, prevertebral collection (39.4\%), psoas abscess (23.9\%) and epidural collection $(45.9 \%)$ were noted. No significant difference was seen between females and males.
\end{abstract}

Conclusions Spinal tuberculosis commonly involves L4/5 level.

Ceylon Medical Journal 2016; 61: 185-188

http://doi.org/10.4038/cmj.v61i4.8387

\section{Introduction}

Tuberculosis (TB) is predominantly a tropical disease with a worldwide mortality of nearly 3 million people a year [1]. About 1-2\% with TB have involvement of the skeletal system and $50 \%$ of them involves the vertebral column [1]. The incidence of spinal tuberculosis is increasing in developed nations [2]. Tuberculosis of the spine is the commonest spinal pathology in India [3].
The prevalence of TB in Sri Lanka is $4.2 \%$ with around 9000 new cases identified each year [4,5]. Back pain, constitutional symptoms, kyphosis, paraparesis, sensory involvement and bowel and bladder dysfunctions are common clinical findings of spinal TB [2]. Cord compression is the most common complication [6]. Back pain is the most frequent presenting symptom of spinal tuberculosis [7]. Early diagnosis and prompt treatment are necessary to prevent permanent neurological disability and to minimise spinal deformity $[8,9]$. Plain radiographic changes associated with spinal TB such as destruction of the inter-vertebral disk space and the adjacent vertebral bodies, collapse of the spinal elements, formation of a 'cold' abscess around the lesion and anterior wedging leading to kyphosis and gibbus formation are seen relatively late $[2,10]$.

For the diagnosis of spinal tuberculosis and its neurological complications, magnetic resonance imaging (MRI) is a more sensitive imaging technique than X-ray and is more specific than Computed Tomography with a sensitivity of $100 \%$ and specificity of $88 \%[2,8,11]$. MRI with contrast is helpful in differentiating from noninfectious causes and delineating the extent of the disease $[24,26,27]$. MRI has a sensitivity of $100 \%$, a specificity of $80 \%$ and an accuracy of $90 \%$ in differentiating TB from pyogenic infection [25]. MRI enables determination of the mechanism for neurologic involvement by demonstrating disc collapse/destruction, cold abscess, vertebral wedging/collapse, marrow edema, and spinal deformities and [11-15].

MRI is also useful in diagnosis and assessment of the treatment response [23].

The objective of the study was to describe the MRI imaging features of spinal TB in a cohort of patients.

\section{Methods}

We retrieved retrospectively data belonging to109 patients diagnosed with spinal TB from 2013 to

${ }^{1}$ Magnetic Resonance Imaging, Neurosurgical Unit, National Hospital of Sri Lanka, Sri Lanka.

Correspondence: ASP, e-mail: <asp31263@hotmail.com>. Received 20 April 2016 and revised version accepted 24 August 2016. and reproduction in any medium, provided the original author and source are credited. 
2016 recorded at Magnetic Resonance Imaging Unit, National Hospital of Sri Lanka. The patients were confirmed clinically, by laboratory investigations and radiogra-phically as spinal TB. Patients without clinical confirmation of TB, incomplete clinical details and equivocal MRI findings were excluded.

MRIs were performed using the following protocol; non contrast T1-weighted (T1W), T2-weighted (T2W), and short tau inversion recovery (STIR) sequences in axial, sagittal, and coronal planes followed by contrastenhanced $\mathrm{T} 1 \mathrm{~W}$ sequences after intravenous administration. (Siemens Avanto 1.5 T, S Harmony $1 \mathrm{~T}$ Erlangan, Germany). We identified the MRI features relatively specific for TB such as preservation of disc space, posterior element involvement, paravertebral abscesses spreading through soft tissue planes, altered vertebral body MRI signals, vertebral body collapse etc $[26,27]$. The data were analysed using SPSS software and chi square test was used for comparison.

\section{Results}

Of the 109 patients recruited $73(67 \%)$ were male. The age ranged from 13 to 81 years, majority were in the 40 to 60 year age group. The presenting complaint in $77.1 \%$ was backache, while 25 patients $(22.9 \%)$ had symptoms suggestive of neural compression. Only 15 $(13.8 \%)$ of our patients had a past or present history of tuberculosis.

Spinal TB could affect one or more vertebrae. Our study found that $75(68.8 \%)$ patients had lesions at a single level. Of the 34 patients with multiple lesions, 27 (79.4\%) had a contiguous lesion and $7(20.6 \%)$ had lesions at separate levels. Analysis of the number of vertebrae involved is shown in the table 1 . Most patients had two vertebrae involved and one patient had 8 vertebrae involved, the highest noted. The commonest vertebral level affected was the lumbar region (49.1\%). Thoracic region was involved in $38.8 \%$, and cervical region $7.2 \%$ and sacral region $4.9 \%$.

L4/5 was the commonest intervertebral disc affected (24.4\%). L5/S1 disc was affected in $12.5 \%$ and L3/4 in $10.8 \%$. The L5 was the most commonly involved vertebral body $(15.2 \%)$ with L4 involved in $14.5 \%$ and L3 in $8.5 \%$. All but one of the 109 patients showed enhancement of the lesion. End plate changes were seen in 105 (96.3\%) patients and erosions were seen in 97 (89\%). Wedging/ collapse were seen only in 27 of the patients.

Fluid collections or abcesses in spinal TB are categorised according to anatomical locations as paravertebral, pre-vertebral, and epidural and psoas. We found that a majority $(65 \%)$ of the patients had a fluid collection in the para-vertebral region. Epidural $(45.9 \%)$, pre vertebral $(39.4 \%)$ and psoas abscess $(23.9 \%)$ were also seen. Of the patients $75.2 \%$ were found to have either a pre vertebral or paravertebral mass without significant cystic components. The prevertebral and paraverterbal fluid collections were most commonly noted at L4 vertebral (12.9\%) and L5 vertebral levels (12.9\%).

Of the patients $26 \%$ had an epidural abscess, without either a paravertebral or prevertebral abscess. Sixty percent of the patients with epidural abscess had neural com-pression. Epidural abscess were present most commonly at L4 (13.7\%) and L5 (13.1\%) vertebrae. Neural canal compression was seen in $84(77.1 \%)$ but only $57(52.3 \%)$ patients had cord compression. The vertebral body was more affected than the posterior element of the vertebrae with only six patients out of the 109 study group having posterior segment involvement. There was no significant difference in MRI findings between males and females.

Table 1. Number of vertebra involved

\begin{tabular}{lcc}
\hline & Frequency & Percent \\
0 & 1 & .9 \\
1 & 4 & 3.7 \\
2 & 68 & 62.4 \\
3 & 11 & 10.1 \\
4 & 13 & 11.9 \\
5 & 8 & 7.3 \\
6 & 3 & 2.8 \\
8 & 1 & .9 \\
\hline Total & 109 & 100.0
\end{tabular}

\section{Discussion}

Out study showed that the majority of the patients were between 40 and 60 years. Some studies suggest that spinal TB commonly affects men of late middle age [5, $28]$. The majority $(67 \%)$ of our patients were male. This finding is similar to what has been reported in other studies $[5,28]$. Twenty five of the 109 patients $(22.9 \%)$ in our study had features of neural compression. The incidence of neurological deficit in spinal TB varies from $23 \%$ to $76 \%$ [32].

There is no consensus on the commonest location of spinal TB in the vertebral column. Most studies suggest that spinal disease is most frequently located in the lower thoracic and lumbar spine, with thoracic disease being commoner in children and adolescents, and lumbar disease is found more commonly in adults $[2,5,12,13,16,29,33$ $39,41]$. Pyogenic Osteomyelitis is more common in the lumbar spine whereas spinal TB is more common in thoracic spine [41]. In our study the highest number of affected vertebrae were found in the lumbar region (49.1\%). In the study done in the Kandy Hospital, the lumbar region was affected in $53 \%$ and the thoracic region was affected in $41 \%$ [5]. They found that the first and second lumbar segments were the commonest vertebrae 
affected (22\%). In comparison, L4/5 was the commonest disc involved (24.4\%). In our study this could be due to several reasons. We analysed only the about patients referred for MRI which is a selected population because patients are referred for MRI when other investigations cannot provide a reliable diagnosis.

Commonly two continuous vertebrae are involved but several vertebrae may be affected, skip lesions, and solitary vertebral involvement may also be seen. In our study $62.4 \%$ had two vertebrae involved similar to other studies [5, 28].

Multiple vertebral involvement (3 or more vertebrae) can be categorized as multiple level lesions (skip lesions, non-contiguous) and multiple contiguous lesions. Multiple non contiguous lesions are more specific for spinal TB but is seen less commonly in about $4-10 \%$ of cases $[1,12,41,26,43,49]$. Seven $(6.4 \%)$ of our patients had multiple non contiguous lesion which is comparable to reports from most studies.

Usually the vertebral body is more frequently affected in spinal TB than the posterior arch. Even though posterior element involvement is rare, it is seen particularly in Asian patients $[2,33,26]$. Our study found only $5.5 \%$ had posterior element involvement. Posterior element involvement is more common in the thoracic spine and many have spinal cord involvement [26]. Three out of the six patients in our study with posterior element involvement of the thoracic spine and five out of the six patients had neural compression.

In conclusion spinal TB in Sri Lankan patients has a predilection for lower lumbar spine, namely L4/5 level.

\section{Conflicts of interest}

There are no conflicts of interest.

\section{References}

1. Hoffman EB, Crosier JH, Cremin BJ. Imaging in children with spinal tuberculosis: A comparison of radiography, computed tomography and magnetic resonance imaging. J Bone Joint Surg Br. 1993; 75: 233-9.

2. Jain AK. Tuberculosis of the spine: a fresh look at an old disease. J Bone Joint Surg Br 2010; 92: 905-13.

3. Tuli SM. Tuberculosis of the skeletal system (Bones, Joints, Spine and Bursal sheaths) 3rd ed. New Delhi: Jaypee Brothers; 2004.

4. World Health Organization, Regional Office for South-East Asia. Tuberculosis in South East Asia: Country profile, Sri Lanka. New Delhi: WHO-SEARO, 2011.

5. Yasaratne BMGD, Wijesinghe SNR, Madegedara RMD, Spinal tuberculosis: A study of the disease pattern, diagnosis and outcome of medical management in Sri Lanka. Indian J Tuberc 2013; 60: 208-16.

6. Desai SS. Early diagnosis of spinal tuberculosis by MRI. J Bone Joint Surg Br 1994; 76: 863-9.
7. Cormican L, Hammal R, Messenger J, Milburn HJ. Current difficulties in the diagnosis and management of spinal tuberculosis. Postgrad Med J 2006; 82: 46-51.

8. Jain AK, Dhammi IK. Tuberculosis of the spine: a review. Clin Orthop Relat Res 2007; 460: 39-49.

9. Taylor GM, Murphy E, Hopkins R, Rutland P, Chistov Y. First report of Mycobacterium bovis DNA in human remains from the Iron Age. Microbiology 2007; 153: 1243-9.

10. Wijesinghe PR, Palihawadana P, De Alwis S, Samaraweera S. Annual risk of tuberculosis infection in Sri Lanka: a low prevalent country with a high BCG vaccination coverage in the South-East Asia Region. WHO South-East Asia J Public Health 2013; 2: 34-40.

11. Moore SL, Rafi M. Imaging of musculoskeletal and spinal tuberculosis. Radiol Clin North Am. 2001; 39: 329-42.

12. Moorthy S, Prabhu NK. Spectrum of MR imaging findings in spinal tuberculosis. Am J Roentgenol 2002; 179: 979-83.

13. Bell GR, Stearns KL, Bonutti PM, Boumphrey FR. MRI diagnosis of tuberculous vertebral osteomyelitis. Spine (Phila Pa 1976) 1990; 15: 462-5.

14. Griffith JF, Kumta SM, Leung PC, Cheng JC, Chow LT, Metreweli C. Imaging of musculoskeletal tuberculosis: a new look at an old disease. Clin Orthop Relat Res 2002; 398: $32-9$

15. Agrawal V, Patgaonkar PR, Nagariya SP. Tuberculosis of spine. Journal of Craniovertebral Junction and Spine 2010; 1: 74-85. doi:10.4103/0974-8237.77671.

16. Maulin MS, Subir NJ, Tuli SM. Musculoskeletal tuberculosis in children. Surgery in Africa. Monthly Review 2011.

17. Vidyasagar C, Murthy HK. Spinal tuberculosis with neurological deficits. Natl Med J India 1996; 9: 25-7.

18. Parvin R, Haque MA, Islam MN, Shaha CK, Uddin SN, Sarkar S, et al. Pott's disease in a young child. Mymensingh Med J 2008; 17: 206-9.

19. Harada Y, Tokuda O, Matsunaga N. Magnetic resonance imaging characteristics of tuberculous spondylitis vs. pyogenic spondylitis. Clin Imaging 2008; 32: 303-9.

20. Jung NY, Jee WH, Ha KY, Park CK, Byun JY. Discrimination of tuberculous spondylitis from pyogenic spondylitis on MRI. AJR Am J Roentgenol 2004; 182: 1405-10.

21. Lee KY. Comparison of Pyogenic Spondylitis and Tuberculous Spondylitis. Asian Spine Journal 2014; 8: 216-23. doi:10.4184/asj.2014.8.2.216.

22. Andronikou S, Jadwat S, Douis H. Patterns of disease on MRI in 53 children with tuberculous spondylitis and the role of gadolinium. Pediatr Radiol 2002; 32: 798-805.

23. Pande KC, Babhulkar SS. Atypical spinal tuberculosis. Clin Orthop Relat Res 2002; 398: 67-74.

24. Ansari S, Amanullah MF, Ahmad K, Rauniyar RK. Pott's Spine: Diagnostic Imaging Modalities and Technology Advancements. North American Journal of Medical Sciences. 2013; 5: 404-411. doi:10.4103/1947-2714.115775. 
25. Na-Young Jung, Won-Hee Jee, Kee-Yong Ha, Chun-Kun Park, and Jae-Young Byun. Discrimination of Tuberculous Spondylitis from Pyogenic Spondylitis on MRI. Am J Roentgenol 2004; 182: 1405-10.

26. Grainger \& Allison's Diagnostic Radiology. “A Textbook of Medical Imaging" $6^{\text {th }}$ Edition. London, Churchill Livingston, 20.

27. Rivas-Garcia A, Sarria-Estrada S, Torrents-Odin C, CasasGomila L, Franquet E. Imaging findings of Pott's disease. Eur Spine J 2009 2013; 22: 567-78. doi:10.1007/s00586-012-2333-9.

28. Ching-Yun Weng, Chin-Yu Chi, Pai-Jun Shih, Cheng Mao Ho, Po-Chang Lin, Chia-Hui Chouc, et al. Spinal tuberculosis in non-HIV infected patients: 10-year experience of a medical centre in Central Taiwan. J Microbiol Immunol Infect 2010; 43: 464-9.

29. Garg RK, Somvanshi DS. Spinal tuberculosis: A review. The Journal of Spinal Cord Medicine 2011; 34: 440-54. doi:10.1179/2045772311Y.0000000023.

30. Kotil K, Alan MS, Bilge T. Medical management of Pott disease in the thoracic and lumbar spine: a prospective clinical study. J Neurosurg Spine 2007; 6: 222-8

31. Hodgson AR, Stock FE, Fang HS, Ong GB. Anterior spinal fusion: The operative approach and pathological findings in 412 patients with Pott's disease of spine. Br J Surg 1960; 48: $172-8$.

32. Shanley DJ. Tuberculosis of the spine: imaging features. Am J Roentgenol 1995; 164: 659-64.

33. Hsu LC, Cheng CL, Leong JC. Pott's paraplegia of late onset: the cause of compression and results after anterior decompression. J Bone Joint Surg Br 1988; 70: 534-8.

34. Weaver P, Lifeso RM. The radiological diagnosis of tuberculosis of the adult spine. Skeletal Radiol 1984; 12 $178-86$

35. Omari B, Robertson JM, Nelson RJ, Chiu LC. Pott's disease: A resurgent challenge to the thoracic surgeon. Chest 1989; 95: 145-50.

36. Kumar K, Saxena MB. Multifocal osteoarticular tuberculosis. Int Orthop. 1988; 12: 135-8.

37. Narlawar RS, Shah JR, Pimple MK, Patkar DP, Patankar T, Castillo M. Isolated tuberculosis of posterior elements of spine: Magnetic resonance imaging findings in 33 patients.
Spine (Phila Pa 1976) 2002; 27: 275-81.

38. Yusof MI, Hassan E, Rahmat N, Yunus R. Spinal tuberculosis: The association between pedicle involvement and anterior column damage and kyphotic deformity. Spine (Phila Pa 1976) 2009; 34: 713-7.

39. Zaidi H, Akram MH, Wala MS. Frequency and magnetic resonance imaging patterns of tuberculous spondylitis lesions in adults. J Coll Physicians Surg Pak 2010; 20: 303-6.

40. Mohammadreza E, Fariborz S, Gholamreza B. Pott's Disease: A review of 58 cases. Med J Islamic Republic Iran 2010; 23: 200-6.

41. Gautam MP, Karki P, Rijal S, Singh R. Pott's spine and paraplegia. JNMA J Nepal Med Assoc 2005; 44: 106-15.

42. Bajwa GR. Evaluation of the role of MRI in spinal Tuberculosis: A study of 60 cases. PakJ Med Sci 2009; 25: 944-7.

43. Korkusuz Z, Binnet MS, Isiklar ZU. Pott's disease and Extra Plueral Anterior decompression. Archives of Orthopaedic and Trauma Surgery 1989; 108: 349-52.

44. Jain R, Sawhney S, Berry M. Computed tomography of vertebral tuberculosis: Pattern of bone destruction. Clin Radiol 1993; 47: 196-9.

45. Watts HG, Lifeso RM. Tuberculosis of bones and joints. $J$ Bone Joint Surg Am 1996; 78: 288-98.

46. Kaila R, Malhi AM, Mahmood B, Saifuddin A. The incidence of multiple level noncontinguous vertebral tuberculosis detected using whole spine MRI. J Spinal Disord Tech 2007; 20: 78-81.

47. Liu GC, Chou MS, Tsai TC, Lin SY, Shen YS. MR evaluation of tuberculous spondylitis. Acta Radiol 1993; 34: 554-8.

48. Sankaran-Kutty M. Atypical tuberculous spondylitis. Int Orthop 1992; 16: 69-74.

49. Pandit HG, Sonsale PD, Shikare SS, Bhojraj SY. Bone scintigraphy in tuberculous spondylodiscitis. Eur Spine $J$ 1999; 8: 205-9.

50. Polley P, Dunn R. Noncontiguous spinal tuberculosis: incidence and management. Eur Spine J 2009; 18: 1096-101. 